\title{
SHORT COMMUNICATION On the Nature of Dielectric Breakdown in Ultra-thin Langmuir Films
}

\author{
V. K. SRIVASTAVA \\ Department of Physics, University of Roorkee, Roorkee, India
}

(Received May, 14, 1976)

Recently ${ }^{1}$ the author proposed the first experimental evidence for Schottky emission dominated dielectric breakdown on the basis of a previous study ${ }^{2,3}$ of the thickness dependence of breakdown field in ultra-thin Langmuir films (about $25 \AA$ to $250 \AA$ ). Nathoo's ${ }^{4}$ recent work has also supported the dominance of Schottky conduction mechanism in the ultra thin 5-layer Langmuir films of stearic acid. However, Agarwal $^{5,6}$ has recently pointed out that the author's evidence ${ }^{1}$ of Schottky dominated breakdown cannot be fully agreed upon because there is no corresponding temperature dependence studies to support the evidence. The aim of the present communication is to draw the attention of the reader to our recent temperature dependence studies. ${ }^{7}$ These studies also support the dominance of the Schottky mechanism of dielectric breakdown in ultra-thin Langmuir films. Thus both the thickness as well as the temperature dependence studies of the breakdown field firmly establish the evidence ${ }^{1}$ originally proposed by the author.

\section{REFERENCES}

1. V. K. Srivastava, Phys. Rev. Letters, 30, 1046 (1973).

2. V. K. Agarwal and V. K. Srivastava, Thin Solid Films, 8 , 377 (1971).

3. V. K. Agarwal and V. K. Srivastava, Solid State Commun., 12, 829 (1973).

4. M. H. Nathoo, Thin Solid Films, 16, 215 (1973).

5. V. K. Agarwal, Thin Solid Films, 22, S3 (1974).

6. V. K. Agarwal, Electrocomponent Sci. Tech., 2, 75 (1975).

7. D. K. Agarwal and V. K. Srivastava, Thin Solid Films, 27, 49 (1974). 

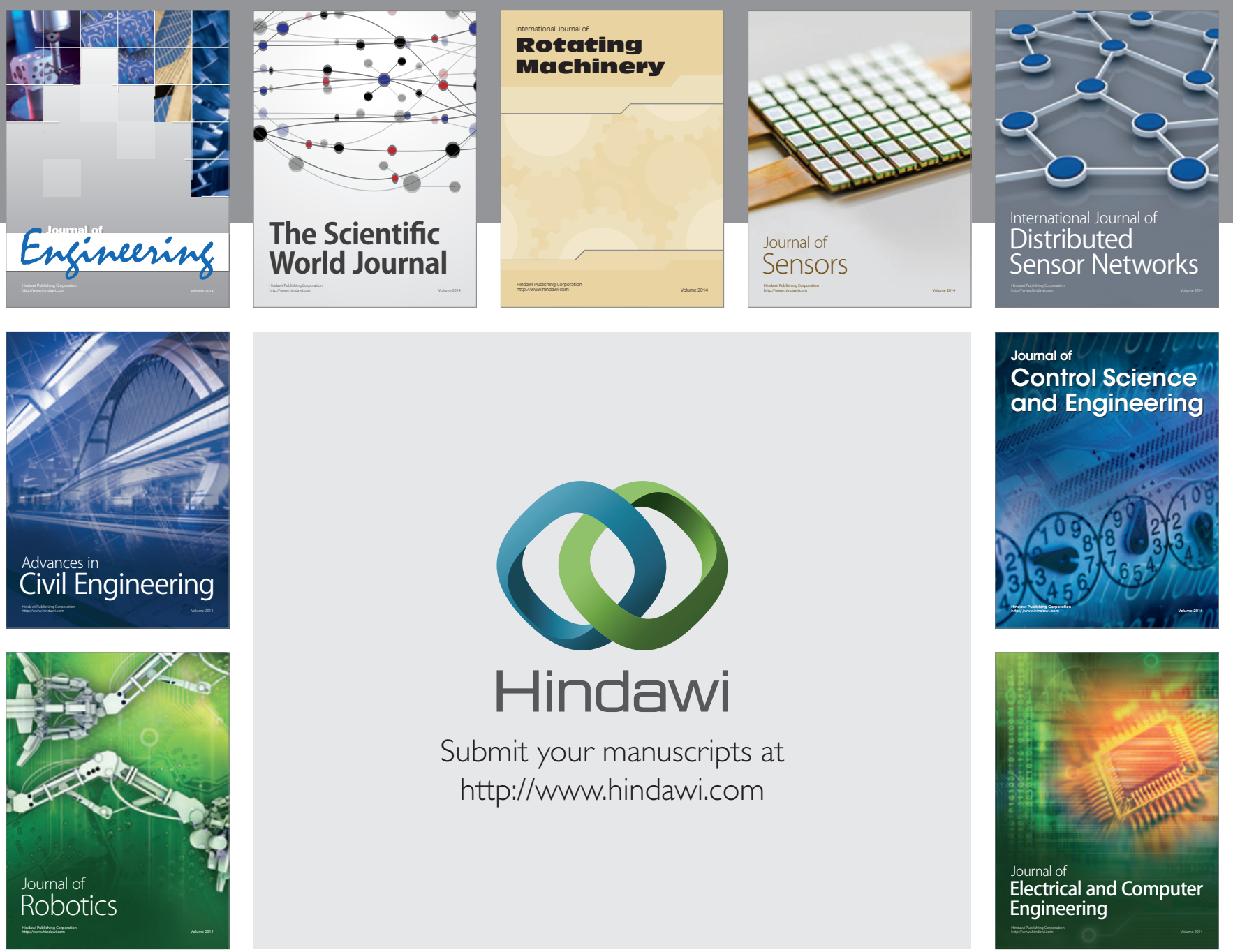

Submit your manuscripts at

http://www.hindawi.com
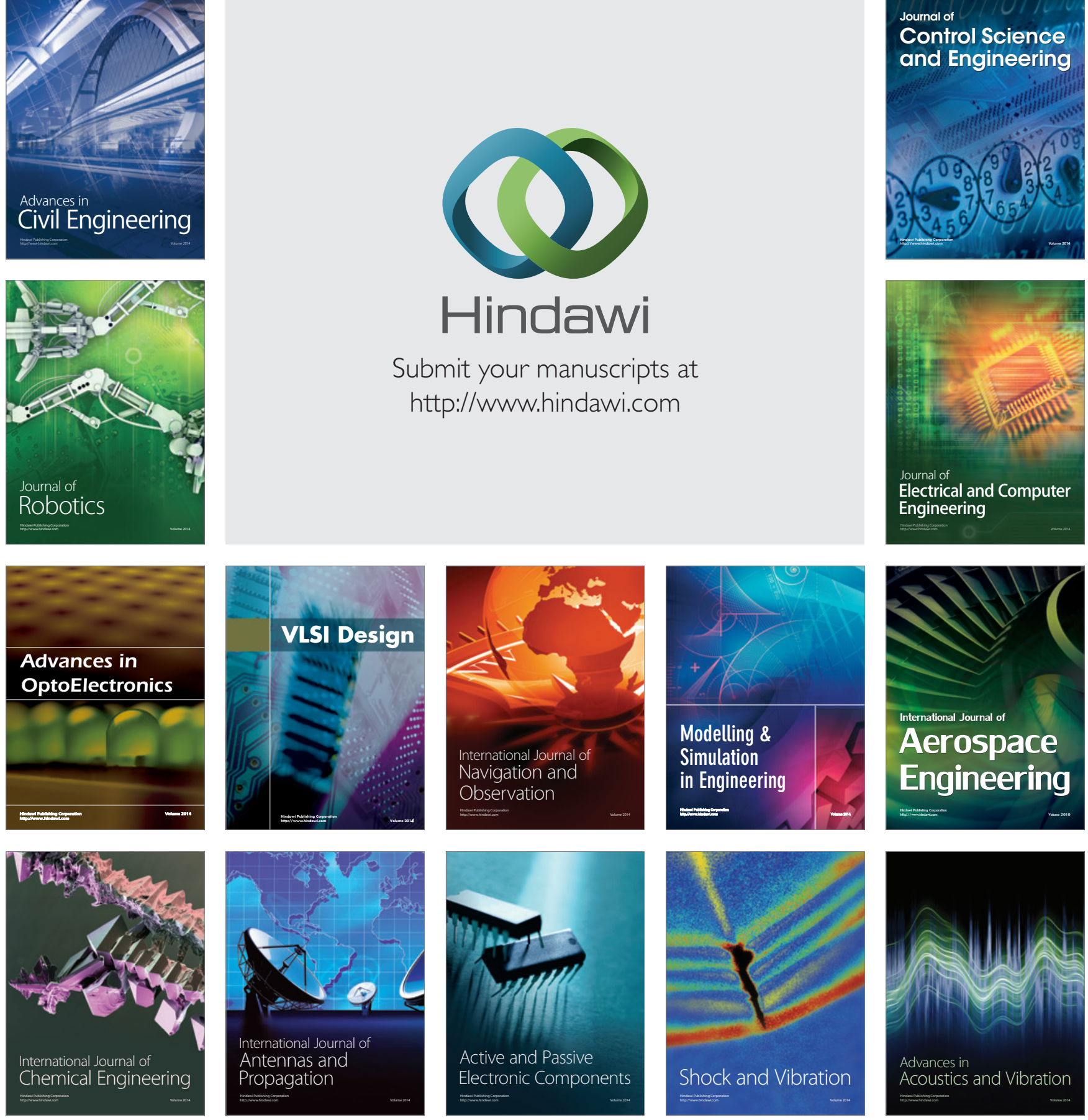